University of Nebraska - Lincoln

DigitalCommons@University of Nebraska - Lincoln

To Improve the Academy

Professional and Organizational Development

Network in Higher Education

1998

Adopting a Strategic Approach to Managing Change in Learning and Teaching

Brenda Smith

Follow this and additional works at: https://digitalcommons.unl.edu/podimproveacad

Part of the Higher Education Administration Commons

Smith, Brenda, "Adopting a Strategic Approach to Managing Change in Learning and Teaching" (1998). To Improve the Academy. 416.

https://digitalcommons.unl.edu/podimproveacad/416

This Article is brought to you for free and open access by the Professional and Organizational Development Network in Higher Education at DigitalCommons@University of Nebraska - Lincoln. It has been accepted for inclusion in To Improve the Academy by an authorized administrator of DigitalCommons@University of Nebraska - Lincoln. 
Smith, B. (1998). Adopting a strategic approach to managing change in learning and teaching. In M. Kaplan (Ed.), To Improve the Academy, Vol. 17 (pp. 225-242). Stillwater, OK: New Forums Press and the Professional and Organizational Development Network in Higher Education. Key Words: change strategies, communication, dissemination, faculty development, organizational development, peer evaluation, portfolios, staff development, student evaluation, universities.

\section{Adopting a Strategic Approach to Managing Change in Learning and Teaching}

\section{Brenda Smith}

The Nottingham Trent University, UK

Universities are having to become more accountable for the quality of the student learning experience. This is taking place in a climate of expanding student numbers, a greater diversity of students, and reduced resources. How then do we motivate faculty, take on board new initiatives, reflect on current practice, and at the same time provide an organizational structure that is supportive and visionary? This article illustrates how a major externally funded project on peer observation led to a change in university culture and facilitated a major structural change to the organization that supports the ongoing development and enhancement of learning and teaching.

Active involvement in higher education in the current climate can be exciting, challenging, rewarding, and, at the same time, frustrating. How can we encourage and support faculty to innovate, share good practice, and enhance the quality of student learning? A picture of what 
is currently happening at Nottingham Trent University is illustrated by the following scenarios. These scenarios are probably typical and occur at various levels within the university.

Scenario one is where individual faculty members, who are intrinsically interested in learning and teaching, spend many hours updating their teaching materials or designing new Web-based materials. They think carefully about student learning and keep up-to-date with pedagogical developments. However, the outcomes are rarely disseminated and faculty may not even be aware of what is happening in the office next door.

Scenario two is at the level of the department where an individual takes responsibility for a new initiative, but in this case other departmental faculty members are involved. The initiative may, for example, be to produce an Information Technology (IT) profile enabling students to monitor and record their progress and demonstrate to external assessors the added value that a particular course offers.

Scenario three operates at the faculty level where the constituent departments collectively plan, deliver, and evaluate a project. The outcomes are thus more likely to be disseminated widely, if only for the fact that there are more faculty spread across different disciplines.

The three given scenarios may be typical of what is happening in other universities, lots of activity covering many different aspects of learning and teaching. However, it may be that we should pause, reflect, and ask some questions.

- What are the key learning and teaching issues within our university?

- What support is available to fund and manage these projects?

- How do we spread good practice?

- Do we know what we are doing across the university?

- Do we have a university strategic plan on learning and teaching?

- Are we being efficient and effective or are we just being busy?

The "picture" emerging from the above questions is likely to be somewhat complex or even chaotic, characterized by a number of uncoordinated activities and little or no dissemination of good practice. We may not even be aware of what is happening down the 
corridor! Educational developers are overworked as the academy demands more, and external pressures force us to provide evidence of quality and value for money. How can universities manage this change process more effectively through a strategic approach?

A major University Project on peer observation of teaching, funded by the Higher Education Funding Council for England (HEFCE) through the Fund for the Development of Teaching and Learning (FDTL), helped focus our attention at the Nottingham Trent University on the above questions. The key focus of the two year project was to set up a system of peer observation/review in different departments across the University. We were eligible to bid for funding because the Nottingham Business School and the Department of Chemistry had been rated as excellent by external quality reviewers. Other departments that had been commended for aspects of good practice were also included. Because external funding could only be obtained for those departments that had already been assessed, the university gave some additional funding to enable the next departments coming up for review to be involved.

The aims of the Project, which we called Sharing Excellence, were to:

- share actively the skills and good practice that led to the designation of "excellence" for learning and teaching both internally and externally,

- encourage the creation of a University-wide culture that recognizes and rewards the value of excellence in teaching and learning and at the same time manage the changes occurring in higher education,

- provide a network of support and exchange of examples of good practice by peer observation of teaching among small "cluster" groups of 4 to 5 faculty,

- provide a more effective system of both faculty and student feedback,

- develop a teaching portfolio.

A number of educational researchers have identified factors that are essential to the success of institutional change in learning and 
teaching (HEQC, 1994; Knapper \& Rogers, 1997). Key factors include leadership commitment, departmental climate, information links, and interpersonal links. Hawkins and Winter (1997) identify five essential change processes that provide the link between operation and strategy: Action, Communication, Ownership, Reflection, and Nurture, the ACORN Model.

The purpose of these processes is to make the link between strategy (top-down) and operation (bottom-up). Strategy needs to be informed by practical realities, so that it is achievable. Similarly, what happens in practical terms must be driven by strategy, in order to be meaningful. Any practical innovation also needs to be supported by institutional systems, or it will become marginalized and unsustainable.

The ACORN Model will be used to illustrate how the Sharing Excellence Project helped in bringing about institutional change at The Nottingham Trent University.

\section{Action}

Change begins with the action of an individual change agent in testing out a new idea. But the change agent needs a suitable vehicle for new ideas, something with sufficient or popular approval, together with appropriate funding. (Hawkins \& Winter, 1997, p. 10)

The idea of peer observation of teaching was not new to The Nottingham Trent University. Two pilot studies had already been undertaken in the Nottingham Business School and the Department of Computing. It therefore seemed opportune that when external funding was available (through a bidding process) peer review of teaching should be the theme. Action has been the cornerstone of the Sharing Excellence Project. Participation of faculty in the peer review scheme was the basis from which the Project outcomes have evolved. Without this specific definable action, the longer term strategic developments would not have been possible.

If action is where change begins, it follows that the caliber of those taking the action will be critical to successful change. The Sharing Excellence Project was based on each department nominating a faculty coordinator to act at the local level, with a project manager 
coordinating the activities of this group across the University. This model of faculty coordinators was extremely successful, as flexibility and ownership at the local subject level proved to be essential.

It is essential that faculties and departments set up teaching and learning groups to enable appropriate strategies and initiatives to be designed, so that teachers feel full ownership for the pedagogical developments in which they are involved. (Smith \& Brown, 1995, p.188)

Action at the local level also depends on winning the hearts and minds of faculty. The organizational structure of Sharing Excellence involved approximately 20 to 65 faculty within each of the department areas (6 departments in year one and 15 in year two). The first six departments were selected in year one, as they had been visited by the external quality reviewers. In year two, the other departments that had been assessed, or that were preparing for external assessment were included. In all but two of the departments, staff volunteered to participate in peer review. In English and Law all faculty participated at the request of the head of the department.

Faculty were grouped into small clusters of 4 to 5 called PTREC groups (Peer Teaching Review and Exchange Clusters). Within the PTRECs each member observed two other faculty teaching and in turn was observed twice in each semester. Participants included junior and senior, and full- and part-time faculty. Good practice identified at the small-group level was passed to departmental and faculty level. Faculty coordinators organized events to discuss themes resulting from observation and issues that needed to be addressed. A very successful whole University "Good Practice Day" on learning and teaching acted as a main focus for faculty across the University to meet together and share experiences. Key aims of this approach were to encourage the enthusiasts and nurture the successes.

The outcomes of this action were the identification and dissemination of good practice. In addition, team work was strengthened, collaboration (across course teams, departments, and faculties) became more evident, and case studies and videos of good practice were produced. 


\section{Communication}

Effective communication, listening, consulting, persuading, encouraging, is perhaps the most essential process which underpins successful change. (Hawkins \& Winter, 1997, p.18)

Because The Nottingham Trent University is one of the largest universities in the UK-with 17,300 full-time, sandwich students (students who spend up to a year in the work place as part of their degree); 5,000 part-time students; and 26 departments grouped into nine faculties - good communication was a challenge. Communication was encouraged in two main ways.

First, presentations were made internally to key network groups (Senior Managers: deans' group, departmental chairs, provost-level administrators, teaching and learning advisory group, course leaders, and principal technicians). Within each department, the faculty coordinator disseminated information, while at University level a steering group of senior managers enabled the upward flow of information. Second, communication was achieved externally through conference presentations and publications, with a website disseminating the materials internationally.

\section{Ownership}

Change requires a sense of commitment throughout the institution. A critical mass of senior support is particularly important. Support on paper is not enough, as changes to organisational structures may be needed. (Hawkins \& Winter, 1997, p.26)

We encouraged ownership by developing both top-down and bottom-up support. At the local level, each faculty coordinator was responsible for between 20 and 65 faculty members. Coordinators organized the peer review process (developed a scheduling system, set up the PTREC groups) and conducted workshops for the faculty in observing classes and giving each other feedback.

To involve senior management in the project, a steering group (chaired by the Deputy Vice-Chancellor) was formed. It included deans, department chairs, provost-level administrators, and a selection of the faculty coordinators. The ongoing, active support of both the 
Deputy Vice-Chancellor and th Dean of the Business School (project director) was paramount. They were both enlightened, proactive, and highly supportive. I held regular meetings with the project director, who helped with agenda items for the steering group. We also worked collaboratively on thinking about issues relating to how the University manages change and gave a joint paper at an international conference. This made a significant difference to the success of the Project. The overall operation and management of the Project is given below.

\section{Operation and Management}

\section{Steering Group}

Deputy Vice-Chancellor, deans, department chairs, project director, project manager,

evaluators, and representatives from the operational group

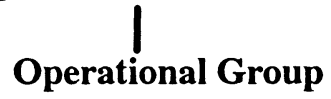

Project manager, project administrator, internal evaluator, student feedback project officer, and faculty coordinators

Faculty Coordinator responsible for 20 to 65 faculty

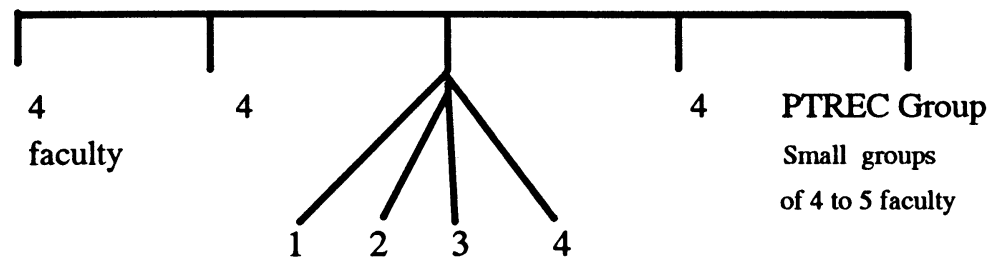

\section{Reflection and Evaluation}

Reflection is far from instinctive. It needs to be forced in every way possible. It must be built into agendas and required in reports. It also requires trust. Reflection must be developed as a habit, the habit of learning. 
The personal habit of critical reflection is essential. It is the basic building block of an institution which is able and willing to respond appropriately to changing needs. This is because personal change lies at the root of all organisational change. (Hawkins \& Winter, 1997, p. 36)

Just as we want our students to become reflective learners, we too needed to apply reflective principles to our work. Indeed, reflection and evaluation became standing items on the agenda for the steering group.

Evaluation, when used in a formative and summative way, enriches project development and increases efficiency and effectiveness. The teams were keen to ensure that an evaluation strategy was developed early to enable formative feedback to occur. In this Project, internal and external evaluators performed different but complementary roles. The internal evaluator focused on faculty and outcomes at the department level and at the level of project management. She analyzed questionnaires, set up focus groups, and interviewed individual staff. In addition she collected information at the faculty Good Practice Days. The external evaluator concentrated on deans, department chairs, and provost-level administrators. He conducted one-toone meetings as well as focus group meetings. This helped to raise awareness of strategic issues relating to the management of organizational change.

Current evaluation from faculty around the University gave insights into practical changes that occurred. Observing other faculty deliver classes highlighted the importance of being aware of the diversity of students' backgrounds and integrating these experiences into the classroom.

It made me think about the level at which I teach.

Peer observation has given me valuable insights into how other lecturers teach, and into students' level of knowledge, skills, and expectations.

A major feature was the benefit faculty gained from having time to meet as a group. It led to a number of faculty course teams completely rethinking the curriculum for a whole year, group of students. 
We have been able to incorporate the benefits into course development from day-to-day teaching, to course and module planning.

We discussed issues on which we are not usually able to find time to have a structured debate.

Peer observation has had a major impact on team building.

Faculty involved in the peer observation process included those who were new to teaching as well as those who were more experienced and senior. All groups of faculty felt they had gained from not only observing others, but being an observer themselves. They saw faculty teach in different ways, use technology, use different teaching techniques, and interact and involve students in a variety of ways.

Sharing good practice is a good thing. Newcomers and part-time staff can learn from experienced members of staff and vice versa.

There had been a long-needed focus on student feedback and participation.

The program also included a widespread system of student feedback. This key and very successful feature was developed by the student coordinator, the only external full-time person to be appointed. Her role included collecting feedback from students in a variety of ways and producing a Staff Resource Pack on Student Feedback. The resource pack contained details about why to gather student feedback, what to gather it about, when and how to gather student feedback, as well as how to analyze and respond to that feedback. The pack was also designed to help faculty carry out an audit and evolve a strategy on student feedback practices. Additionally, students' views were recorded using videos. The following comments reflect some of the student views and highlight the value of involving students as key players in the learning process.

The more faculty talk to each other about teaching the better it is for us. Peer review seems like a useful way of swapping ideas and encouraging each other.

Faculty in our department seem to have been quite heavily involved in the project this year. I think it's made them more self-conscious. Well...more conscious of what they're actually trying to achieve in each session. 
It's strange how little changes make such a difference to a lecture. The only obvious effect was that the overheads were bigger and clearerbut somehow the way she explained things became more straightforward as though she had thought through everything really thoroughly.

Listening to our students has been extremely valuable, and many departments are now using the staff resource pack to carry out an audit of existing practice and rethink some of the methods previously used. There has in the past been an overreliance on questionnaires. Such instruments are only as good as the questions used, which may or may not be on the student agenda. The use of focus groups, student diaries, structured feedback sessions, log books, and shadowing, for example, give a much fuller picture of issues that concern students. However, another key feature of the pack has been to ensure that we "close the loop" by encouraging us to feed back to students what has changed, or not changed, as a result of their comments. The full pack can be accessed via the Sharing Excellence website (Student Feedback, http://www.celt.ntu.ac.uk).

Another significant benefit of the ongoing evaluation and reflection was that it fostered strategic thinking around how the University manages change and innovation in learning and teaching.

\section{Nurture}

An innovation will only outlive the enthusiasts if lasting systems and structures support it. The desire to improve teaching and learning, for example, must be supported by recruitment and promotional policies as well as staff development activities. This "nurture" needs to be in mind throughout the change process, not just at the final stage. (Hawkins \& Winter, 1997, p. 40)

The essential challenge for the Sharing Excellence Project was to move from the successful practice to a state where new methods had deep roots in the University. This meant that the innovation must be incorporated in institutional systems and structures. Marginal activity must be brought into the mainstream of university life.

The steering group was the focus of issues relating to nurture. We questioned what the University was doing in relation to learning and teaching at every level of the organization. How would these activities 
be disseminated and what structural support was available to ensure embedding of good practice and a continuation of relevant issues? As a University, there was a lot of activity (see the scenarios at the beginning of the article), but the overall picture was difficult to see. Because no one person had an overview of all the activities, the steering group found it difficult to determine effective dissemination strategies. A blank table with key headings was devised to enable essential project information from across the University to be collated in a systematic way and then posted on the website of the Centre for Learning and Teaching (CeLT).

In terms of structure, the network of faculty coordinators was extremely effective. They had good interpersonal skills and were able to interpret how materials and operations needed to be modified to fit into local subject cultures. The importance of being able to adapt at the department level was vital. This can be illustrated by a very simple example. A number of peer review sheets were designed for use during the observation of teaching. The faculty coordinators were trying to make a decision about which one to use, but we could not agree. The Humanities staff wanted the "clean" sheet of paper while the Engineers favored the tick-list. However, we realized it did not matter; the most effective review sheets were the ones that the faculty felt to be the most useful. This is a lesson we carried with us: a general framework can be devised centrally, but when local ownership is allowed the outcomes are more effective.

Case studies of good practice, videos of staff and students, a special edition of our Teaching And Learning Kaleidoscope Journal TALK devoted entirely to the Sharing Excellence Project, and our specially designed website (http://www.celt.ntu.ac.uk) have helped to disseminate the outcomes, to share good practice, and, therefore, to nurture and embed the outcomes. A draft copy of a teaching portfolio was developed by a small team of faculty coordinators for individual faculty to complete on a voluntary basis. This is currently being piloted by some faculty. At the personal level, it serves as a record of continuing professional development, a source of evidence for claims for promotion and external subject reviews, as well as a document to support professional teaching accreditation by external bodies. At the institutional level, it generates a climate of scholarship in teaching and 
emphasizes the value of teaching and learning within the University.

The following recommendations are based on the success of this project in helping the University develop a strategic approach to teaching and learning.

1. A well-planned project with clear outcomes, milestones, and with an evaluation and dissemination strategy enabled the team to start on time and work to clear targets. Sometimes innovations are started by a group of individuals with good ideas without clearly thinking through implications, resources required, and with little consideration for staff release time to carry out the activity appropriately.

2. It is necessary to seek funding, as most innovations and developments require adequate resources if they are to succeed. Funding for the Sharing Excellence Project was granted by the Higher Education Funding Council for England, as well as some internal funding by the University. Resources helped to ensure that tasks were achieved. The funding was used mainly for part-time faculty and to enable other faculty to be released from some teaching and spend time on the project. It also funded the faculty Good Practice Days, provided secretarial support, and paid for conference attendance and for the student coordinator. Universities need to take the issue of proper funding for learning and teaching seriously if they are to demonstrate publicly that they value learning and teaching and not just research. Using funding to encourage teams/departments, not isolated individuals, was effective and efficient.

3. It was essential to have good project management, with an efficient administrator and a team of faculty coordinators working at the department level who could motivate and cajole, as well as interpret and amend material to each department. Additionally, a network of people across the University, working and learning together and sharing their talents and materials, has a synergistic effect as well as producing more materials. Genuine partnerships with students, employers, the 
career service, computing services, and library information services may require a new mind set. However, the benefits of working together through open critical reflection have long-term benefits and should be encouraged within any institution.

4. Strong and active support from senior management is essential. The Deputy Vice-Chancellor chaired the steering group and was very supportive, while the project director discussed issues at regular meetings with the project manager and had an invaluable input in shaping strategies. Deans, department chairs, and provost-level administrators need implicitly and explicitly to support learning and teaching, for if they take learning and teaching seriously in public statements and in practice, then so will their staff.

5. There is a need to reward excellence in learning and teaching. The economic benefits of good teaching, in terms of attracting and retaining students, cannot be underestimated.

In books by Halpern et al. (1994) and Katz and Henry (1993) we can see how teachers' ability to reflect on teaching and learning has emerged as a focus for employment and promotion discussions, for professional development, and for assessing scholarly competence. (Brookfield, 1997, p. 128)

To ensure that good quality learning and teaching is taken seriously, staff should be rewarded for their efforts and excellence in teaching acknowledged by promotion through to Professor level. At the Nottingham Trent University, a new pay and promotions policy was announced within the University, which allowed promotion on the grounds of excellence in teaching and included promotion to a full Professor.

6. Finally, the development of a strategic infrastructure with high levels of awareness throughout the University is important. This has included well-organized dissemination of training and materials, close liaison between coordinating staff from different departments, and a network of support from 
both senior management and colleagues at local level. This network of awareness and support is essential if project activities are to be implemented effectively and changes embedded into faculty structures. Change must be incorporated in faculty mission statements, curriculum frameworks, and teaching practices. To accomplish a thoroughgoing change, a critical mass of senior support is needed. This takes time.

Two of the most successful outcomes of the Project was a Centre for Learning and Teaching (CeLT), and the appointment (at senior level) of nine faculty learning and teaching coordinators (one person from each of the nine faculties). These faculty coordinators will spend one day per week in CeLT and another day working with faculty staff. Their first task is to write a strategic plan on learning and teaching at both faculty and university level giving a focus to what we want to achieve in the next five years. This group has formed the University Learning and Teaching Advisory Group and, in addition, manages and operates faculty Learning and Teaching Groups. The learning and teaching advisory group reports to the academic review and development committee and on to the academic board. The support structure is therefore embedded both upwards and downwards.

The Sharing Excellence Project has enabled the University to focus attention on the future direction of learning and teaching. A new Centre (CeLT) was formed, learning and teaching coordinators appointed, and there has been a culture shift with more deans and department chairs acknowledging and supporting issues relating to learning and teaching. A new learning and teaching development fund of half a million U.K. pounds has been set up by the Deputy ViceChancellor. This fund is designed to encourage further developments from teams of faculty through a formal bidding process. Other outputs have included case study material, videos of staff and students, a staff resource pack on student feedback, a draft teaching portfolio, conference presentations, articles, and a website. A network of support has developed across the University, with more staff reflecting on their teaching and discussing issues relating to the student learning experience. 
The responsibility for change rests on the shoulders of every individual who wishes to survive in the turbulent climate of the 21 st century. Each person can be an influential 'champion' on the character map of their own institution, department or work group. Nobody is without influence.

Despite the complexity of the change process, the features of the effective change agent can be summarised in seven 'winning characteristics' [See Appendix]. Those who take them to heart are likely to stand out from the crowd. In uncertain times it will be clear they have succeeded in mastering change. (Hawkins \& Winter, 1997, p. 46)

Although we have learned a great deal from this project, we realize that incorporating long-lasting change is an ongoing process. In addition to reflecting on what we achieve, we will continue modifying our strategic vision to ensure that we have the appropriate systems in place to support and nurture future developments.

My thanks go to all the staff involved in the Sharing Excellence Project for their enthusiasm, dedication, and willingness to share their teaching excellence with others.

\section{References}

Brookfield, S. (1995). Changing the culture of scholarship to the culture of teaching: An American perspective. In T. Schuller (Ed.), The changing university (pp. 128-138). Buckingham, UK: The Society for Research into Higher Education (SRHE) and Open University Press.

Halpern, D. F. \& Associates. (1994). Changing college classrooms: New teaching and learning strategies for an increasingly complex world. San Francisco: Jossey Bass.

Hawkins, P., \& Winter, J. (1997). Mastering change: Learning the lessons of the enterprise in higher education initiative. Sheffield, UK: Department for Education and Employment (DfEE).

Higher Education Quality Council (HEQC). (1994). Choosing to change. London: HEQC.

Katz, J., \& Henry, M. (1993). Turning professors into teachers: A new approach to faculty development and student learning. Phoenix, AZ: Oryx Press.

Knapper, C., \& Rogers, D. (1994). Increasing the emphasis in Ontario universities. Ontario: Task force on resource allocation, OCUA.

Smith, B., \& Brown, S. (1995). (1995). A manifesto for research, teaching and learning. In B. Smith \& S. Brown (Eds.), Research, teaching and learning in higher education (pp. 187-190). London: Kogan Press. 


\section{Contact:}

Brenda Smith

Director, Centre for Learning and Teaching

The Nottingham Trent University

Burton Street

Nottingham NG1 4BU

UK

$44115948-6547$

Brenda.Smith@ntu.ac.uk

Brenda Smith is Director of the Centre for Learning and Teaching and Project Manager for the Sharing Excellence Project at the Nottingham Trent University. She chairs the University Learning and Teaching Advisory Group and manages nine faculty learning and teaching coordinators across the university. She is also responsible for encouraging, coordinating, and disseminating innovation and good practice in learning and teaching across the University. Brenda has written widely on teaching and learning including authored and edited books and articles. Additionally, she has facilitated many workshops on learning and teaching both in the UK and internationally, including work in Singapore, South Africa, Hong Kong, Azerbaijan, and the Philippines. 


\section{Appendix}

Hawkins and Winter (1997), have produced the seven winning characteristics of the successful agent of change. This is given in full below. Does your university successfully achieve the seven winning characteristics?

\section{HAS A SENSE OF PURPOSE}

Is fully aware of the need to change.

Has a vision of what can be achieved.

Is realistic about the scale and timescale for change.

Is flexible about the means to achieve the change.

Understands the change process itself.

\section{HAS THE CAPABILITY TO ACT}

Has leadership and interpersonal skills, with political awareness.

Has a means to promote change (i.e., a role, a project, resources, or influence).

Has knowledge of the institution, its history, and its influential characters.

Develops an influential team.

\section{SELLS SUCCESS}

Ensures that early successes are achieved.

Focuses on spreading successful practice.

Has a clear communications strategy for selling success.

Builds appropriate networks to facilitate communication.

Understands others' priorities in order to offer them clear benefits.

Offers support and encouragement, not another problem.

\section{IS STRATEGICALLY CONNECTED}

Is well connected with sources of power and influence.

Builds a critical mass of senior support or a senior champion.

Ensures senior links will last and do not depend on one individual.

Understands the senior management agenda and sells benefits.

Makes the link between strategy and operations.

Encourages senior people to learn by experience. 


\section{IS CRITICALLY REFLECTIVE}

Builds a non-threatening environment.

Encourages learning from failure as well as success.

Makes critical reflection on every level (i.e., personal, team, departmental, institutional).

Records important learning points so they don't depend on memory.

\section{BUILDS SUPPORTIVE STRUCTURES}

Ensures mechanisms are in place to continue the innovation and to spread it.

Embeds the innovation by making it an important part of the wider strategy.

Supports the innovation with appropriate resources for teaching and learning.

Ensures that future innovation will be supported and embedded. Develops processes to respond to the needs of institutional "stake holders."

\section{IS OPPORTUNISTIC}

Predicts and uses external and internal levers for change, including political forces.

Makes use of all available resources, including students, employers and alumni.

Notices and secures external funding which will support (not dictate) the change.

Encourages innovation, for example, with protected money for innovative projects.

(Hawkins \& Winter, 1997, p. 47). 